\title{
IMÁGENES Y RELATOS DEL PASADO Y EL PRESENTE: EDUCACIÓN Y MEMORIA DE NIÑOS BOLIVIANOS EN BUENOS AIRES ${ }^{1}$
}

Gabriela Novaro ${ }^{2}$

\begin{abstract}
Resumen: Desde el año 2010 trabajamos en un barrio cercano a la ciudad de Buenos Aires con un alto componente de población migrante procedente de Bolivia. Se trata de un espacio donde se registra un fuerte proceso de territorializacion de la identidad y los adultos expresan reiteradamente la preocupación por la continuidad de la identificación con Bolivia en las nuevas generaciones. Nos centramos aquí en las imágenes y los relatos históricos que interpelan a los niños bolivianos en contextos escolares, familiares y comunitarios.
\end{abstract}

Palabras clave: Memoria. Identificación nacional. Imágenes. Relatos. Comunidades; Escuela.

\begin{abstract}
Since 2010 we work in a neighbourhood, close to the city of Buenos Aires, with a high component of Bolivian inmigrants. It is a place with a strong process of identity territorialisation and adults express oftenly their concerns for the continuity, in the younger generations with Bolivian identifications. We focus here in the images and historical accounts that face-encounter bolivian children, in school, family and community contexts.
\end{abstract}

Keywords: Memory. National identification. Images. Accounts. Communities. Schools.

\section{INTRODUCCIÓN}

Los niños y jóvenes migrantes y las llamadas segundas generaciones constituyen un colectivo fuertemente tensionado por los procesos de construcción de la memoria y la transmisión intergeneracional de referencias de identificación. Estas tensiones se experimentan en términos aún más complejos en contextos desigualdad y de disputa en torno a las referencias étnicas y nacionales.

En este texto procuramos avanzar en torno a esta temática a partir de una investigación que desde el año 2010 desarrollamos en un barrio de la localidad de Escobar conocido como el barrio boliviano o Villa bolita ${ }^{3}$. El trabajo se realiza en contextos familiares, comunitarios y escolares.

\footnotetext{
Una versión anterior de este texto fue presentada al XI Congreso Argentino de Antropología Social, Rosario 2014 Universidad de Buenos Aires - CONICET. E-mail: gabriela.novaro@gmail.com

Si bien muchos vecinos identifican el barrio con ese nombre, es importante advertir que gran parte de la población que lo habita es en realidad descendiente de migrantes.
} 
En los últimos años los estudios sobre antropología y migración se han incrementado en Argentina. Muchos de ellos atienden a los procesos de identificación (abordando cuestiones cercanas a la memoria) pero pocos a la situación de la niñez y la juventud migrante y las llamadas segundas generaciones

La población procedente de Bolivia se caracteriza por la inestable inserción en el mercado laboral, la segregación territorial, las recurrentes situaciones de discriminación. En este contexto el fortalecimiento de redes entre migrantes y el asentamiento en determinados barrios o zonas (en este caso de Buenos Aires) obedece a la intención de fortalecer vínculos internos y mantener la continuidad de ciertas referencias nacionales, étnicas y regionales. Junto a ello se registra un fuerte proceso de asociación que suele visibilizarse en festividades, programas radiales, edición de periódicos. En todo esto sin duda advertimos discursos y experiencias que remiten a procesos de construcción de la memoria. Es importante considerar que esto se da en una situación donde la normativa migratoria cambia, y al menos en el plano legal (ley $\mathrm{N}^{\circ} 25.871 / 03$ ), en Argentina habilita un discurso de reconocimiento de derechos y cierta valoración identitaria (Novik, 2008)

En el plano educativo se registra la fuerte impronta del modelo nacionalizador con que se conforma el sistema educativo y su vigencia actual, a pesar de las nuevas retoricas de la inclusión y la interculturalidad.

Los niños migrantes procedentes de Bolivia en Argentina se hallan masivamente insertos en las escuelas según datos censales. Advertimos no obstante que esto no es una garantía de inclusión en condiciones de igualdad. Por un lado, la escuela los sigue interpelando muy fuertemente desde el discurso nacionalista y definiéndolos como extranjeros. La exclusión educativa de estos niños no es un dato evidente, sino que se advierte en los particulares modos de estar "dentro" del sistema en un proceso al que en trabajos previos caracterizamos como una forma de inclusión subordinada. Entre otras manifestaciones de esta subordinación hemos registrado el desconocimiento o desvalorización de sus trayectorias escolares en Bolivia, el silenciamiento de sus palabras, la confrontación de estilos comunicativos, la folklorizacion estereotipada de sus pertenencias y saberes (Novaro-Diez 2012; Novaro, 2012). En este trabajo nos detenemos en un aspecto de la inclusión-exclusión escolar claramente vinculado a los procesos de construcción del pasado: el modo en que sus referencias de identificación se presentan en contextos familiares y comunitarios y la forma en que los mismos se articulan, entran en tensión o confrontación con la construcción social del pasado que los niños realizan en las fiestas y las clases de historia de la escuela.

Para ello comenzamos a explorar en el campo de estudios sobre la memoria teniendo en cuenta la relación que diversos autores señalan entre 
historia vivida y la historia escrita (Halbwachs, 2011), a lo que agregamos la necesidad de distinguir entre el pasado relatado y recreado. En situaciones de transmisión intergeneraional nos interesa atender a las distinciones y articulaciones entre formas de construcción de la memoria en situaciones cotidianas informales de mayor espontaneidad y en otras más institucionalizadas, formalizadas y ritualizadas (como suelen ser las escolares).

Es necesario considerar distintas posiciones en torno a la función de la escuela en este aspecto. Mientras para algunos la escuela constituye un espacio fundamental de transmisión de lo que se considera la memoria legitima de la nación (Pollak, 1989), para otros, representa un espacio fundamental de disputa por la memoria (Carretero, Rosa, Gonzalez, 2013)

Lejos de suponer una visión polar entre lo que sucede en contextos familiares-comunitarios y escolares, nos interesa tanto atender a la especificidad de los distintos ámbitos como a su mutuo atravesamiento.

El TRABAJO DE CAMPO ${ }^{4}$.

El llamado "barrio boliviano de Escobar" se ubica a $50 \mathrm{~km}$ al norte de la Ciudad de Buenos Aires, Argentina. Constituye una zona asociada a la producción hortícola y con un alto componente de población migrante procedente de la zona andina de Potosí.

En principio me centré en el contacto con dos organizaciones que nuclean a migrantes (la Colectividad Boliviana de Escobar, y la Asociación de Mujeres Bolivianas de Escobar). Registré numerosos contextos de interacción: festividades y encuentros en las organizaciones, relaciones cotidianas familiares, vínculos de los padres con las escuelas de la zona. Con las mujeres de la Asociación reconstruí narraciones biográficas atendiendo a sus recuerdos sobre Bolivia, sobre la migración y los primeros años de asentamiento en Buenos Aires, sobre la forma de crianza y la escolaridad de sus hijos en Bolivia y en Argentina. Me conecte además con las dos escuelas de la localidad donde observé numerosas situaciones escolares, releve proyectos institucionales, registros, carteleras, libros de memorias, festividades y de clases de ciencias sociales y realicé entrevistas a distintos actores educativos.

A partir de este relevamiento me interesa señalar las continuidades y rupturas en la construcción del pasado en uno y otro ámbito, en vinculación al deseo de inclusión/distinción con que los padres proyectan el futuro de las

\footnotetext{
Esta investigación se desarrolla en el marco del Programa de Antropología y Educación, Facultad de Filosofía y Letras /Universidad de Buenos Aires, con el apoyo de esta universidad, el Conicet y la Agencia Nacional de Promoción Científica y Tecnológica.
} 
jóvenes generaciones, y la lógica de visibilizacion/marcación/ocultamiento que advierto en las escuelas de la localidad.

\section{Migración y MEMORIA EN EL BARRIO, LAS ORGANIZACIONES Y FAMILIAS 5}

En "El barrio boliviano" o "Villa bolita" se registra un fuerte proceso asociativo y de afirmación de la identidad nacional. Es importante advertir que esto se da en un contexto general de discriminación y pobreza.

Este barrio, fuertemente asociado a la producción y la comercialización fruti-hortícola, fue habitado hasta mediados del siglo XX sobre todo por migrantes portugueses, italianos y japoneses. La población procedente de Bolivia, fundamentalmente de zonas rurales del departamento de Potosí, comienza a llegar en la década del 60 . Esta población generalmente se incluyó en el trabajo rural a partir de relaciones de parentesco y paisanaje (Benencia. 2008) A mediados del 80 surgieron los intentos de crear una asociación: La Colectividad Boliviana de Escobar. Esta se formaliza en 1991. Hoy nuclea cerca de 1000 miembros y es propietaria de importantes edificios vinculados a la comercialización de productos frutihortícolas y vestimenta. Alterna, según investigaciones previas en la zona, objetivos de integración a la sociedad nacional y reforzamiento de identidades distintivas (Pizarro, 2007).

El lugar de la Colectividad es central como convocante y sostén de festividades que funcionan como fuertes marcantes de nacionalidad; año a año el carnaval, el día de la independencia de Bolivia, el aniversario de Potosí entre otros son ocasión para la organización de multitudinarios eventos que buscan mantener "latente la Identidad Boliviana, preservando las costumbres y tradiciones del solar patrio...y manifestaciones culturales propias de nuestras raíces bolivianas". (www.comunidadbol.com.ar, 2002)

Mucho más pequeña que la Colectividad, la Asociación de Mujeres Bolivianas de Escobar (en adelante la Asociación), formaliza su creación en el 2005. Reúne fundamentalmente mujeres de condición humilde y en muchos casos con escazas experiencias de escolaridad. Esta institución recupera y recrea formas de participación política de Bolivia, explícitamente buscando reproducir el modelo de los Centros de Madres, tipo de asociación muy extendida en ese país, vinculada a tareas de reproducción, emprendimientos productivos, reparto de comida, etc. ${ }^{6}$. La Asociación de Mujeres funciona

Muchas de las cuestiones a las que se alude en este punto han sido abordadas en textos anteriores (Novaro 2014). En este caso las ponemos en función de precisar los procesos de construccion de la identidad y la memoria en la localidad. Nos referimos a ellas además a partir de información no sistematizada anteriormente y nuevos registros de los años 2014 y 2015.

6 Los Centros o Clubes de Madres aparecen vinculados tanto a propuestas que dicen propiciar el fortalecimiento del lugar de la mujer entre los sectores vulnerables, como a estrategias de asistencialismo, control y penetración de la modernidad, el Estado, los organismos internacionales y la iglesia en las comunidades andinas (González Guardiola, 2000; Silvia Rivera, 2004) 
como un espacio convocante para actividades de promoción social y cultural, asistencia a las socias más pobres, asesoramiento sobre documentación, organización de eventos y un programa de radio y, sobre todo en los últimos años, gestión de diverso tipo de subsidios.

La dinámica de la desigualdad y las lealtades locales, regionales y étnicas atraviesan estas organizaciones.

En esta situación la prédica del nacionalismo, la permanente alusión a Bolivia (sobre todo en las celebraciones) adquiere connotaciones muy diversas: aglutinamiento, reforzamiento de lazos sociales y políticos, resistencia y denuncia de situaciones de discriminación y violencia. Pero adquiere también connotaciones ligadas a la disolución de lealtades regionales y étnicas, y encubrimiento de desigualdades, ya que resultan cada vez más evidentes las situaciones de fragmentación al interior de la Colectividad ${ }^{7}$.

Registramos también procesos que podrían ser interpretados como de cerramiento de la colectividad sobre sí misma, materializados por ejemplo en el paulatino y constante crecimiento del muro que rodea los terrenos de la Colectividad del barrio, en iniciativas como la construcción de un barrio cerrado "Cerro Rico", loteado mayormente entre población boliviana y también, en un proyecto sobre el que se habla mucho en la Colectividad pero que no se ha concretado luego de varios años: la creación de una escuela de la Colectividad, llamada alternativamente "Escuela propia", "Escuela Boliviana" "Escuela andina".

En los tránsitos cotidianos por el barrio se despliegan estas mismas marcas de continuidad: las pinturas de los edificios, los nombres de muchos comercios (Kiosko "La Paz", remises "Sin fronteras", ómnibus "Potosí", "Odontología integral latinoamericana")

En las organizaciones se registra la constante puesta en acto de la doble pertenencia: las recurrentes marchas con banderas argentinas y bolivianas en las festividades hablan de la vigencia de un lugar dejado y también de la apropiación de la simbología del que ahora se habita, marcan y proyectan un territorio como propio y acompañan las recurrentes alusiones al "allá" y el "acá" (Novaro, 2014). Los sentidos dados al territorio, al dejado y al ahora habitado, evidentemente son fuertes elementos en la construcción de la memoria y la identidad

Las referencias a Bolivia en tiempo presente son también recurrentes en los relatos de vida realizados con las mujeres de la Asociación. La sensación es que queda fijada e idealizada la imagen del país de origen que corresponde a cuando los adultos se fueron, en muchos casos más de diez años atrás (las características de la escuela rural, los ritos, las prácticas de

Se registra la fuerte diferenciación entre propietarios de terrenos, comerciantes, arrendatarios, peones, pequeños comerciantes; también entre quienes tienen lazos políticos con el Estado argentino y boliviano y quienes carecen de estas relaciones. 
producción agrícola, la seguridad, la lengua, la disciplina escolar). Esta memoria se actualiza para muchos en el permanente ir y venir de uno a otro país y en las múltiples redes tejidas entre Bolivia y Argentina. En general se trata de una memoria idealizada que corresponde con la imagen de sujetos honestos, laboriosos, confiables. Estas imágenes se estructuran por contraste con estereotipos negativos instalados en Argentina sobre esta población: sumisos, dejados, pasivos, dependientes de los subsidios estatales.

La construcción de la identidad parece desplegarse en este contexto en relación a la tensión entre continuidad y cambio, asociado a representaciones sobre "lo boliviano" y "lo argentino" caracterizados a partir de atributos vinculados a la dualidad tradición-modernidad. Lejos de valoraciones fijas y constantes, junto con el deseo de inclusión en lo que se asocia a lo nuevo, se registra la nostalgia por la continuidad y la tradición, la tranquilidad y la confianza atribuidos a Bolivia, que se opone a las imágenes de inseguridad y desconfianza vinculadas a Argentina (Novaro, 2014).

En cualquier caso, en la situación analizada, y en una lógica que articula constantemente el allá y el acá, es evidente siguiendo a Candau (2008) que la reconstrucción del pasado se realiza a partir de las necesidades del presente, de la imagen que se intenta construir del grupo con rasgos de continuidad en una situación de permanente cambio. Para comprender el formato esencializador y la tendencia al reforzamiento del propio grupo resultan sugerentes las apreciaciones de este autor sobre la pregnancia de los orígenes en la memoria social migrante que para facilitar la construcción de una identidad grupal se inclina por los símbolos posibles de reificación y por los que acentúan la permanencia del origen. Refiere a que en contextos de migración la construcción de la identidad se organiza alrededor de la memoria de su vieja casa como una negación simbólica de la migración. La importancia de la dimensión espacial en los procesos de construcción de la memoria y de sentidos de colectividad en contextos de migración se hace de esta forma evidente.

Es posible suponer que entre la población mirante en general, y en este caso en particular para la población procedente de Bolivia, la relación entre memoria, identidad y territorio resulta evidente en el hecho de que la pertenencia nacional se marca a partir del nacimiento en un espacio que se ha dejado (donde por otra parte las identidades parecen fuertemente atravesadas por la lógica regional y étnica), pero al que - como rasgo de identificación - se alude de manera permanente en el nuevo país de residencia. Nos preguntamos entonces si las alusiones a Bolivia, en este contexto, se transforman en sí mismas en un acto de memoria y de qué manera operan en las jóvenes generaciones. 
RELACIONES INTERGENERACIONALES Y CONSTRUCCIÓN DE LA MEMORIA EN FAMILIAS Y ORGANIZACIONES MIGRANTES

En el trabajo hemos atendido particularmente a las preocupaciones de los adultos migrantes por la transmisión de la referencia a Bolivia en los niños nacidos en Bolivia que se han criado en Argentina y en los que muchos definen como "bolivianos de segunda generación" o "hijos de....

Resulta significativa la convocatoria a los niños y jóvenes a ciertas prácticas organizadas por la Colectividad que funcionan como eventos de visibilización de la pertenencia nacional (y en algunos casos también de la pertenencia étnica); el futbol (donde se utilizan las camisetas de la selección boliviana), los grupos de danza y de música que participan en las festividades (con ritmos, instrumentos y coreografías andinas). El siguiente registro del dia de la independencia de Bolivia muestra la centralidad de los niños en estas convocatorias ${ }^{8}$.

Cuando llegamos al predio donde se hace la fiesta el locutor está hablando sobre el antiimperialismo, el estado plurinacional de Bolivia, etc. Muchos de los asistentes portan escarapelas de la bandera boliviana con un pequeño lazo "argentino" encima, otros tienen una escarapela boliviana más grande abajo y una argentina más pequeña encima....Entre los conjuntos que desfilan abundan las banderas bolivianas, la wiphala y la argentina y diversos estandartes. Estos símbolos son portados tanto por adultos como por niños

Saludo a las mujeres de la Asociación y me quedo en el grupo.

Un hombre que he visto en las reuniones me pide que le saque una foto a su hija que esta vestida con una pollera y una blusa típica de las mujeres andinas, le pone un sombrero de copa blanco. Se para frente a un arco que han adornado con flores y aguayos. La nena parece tener un poco de vergüenza pero él insiste... Las mujeres marcharon con una virgen, un estandarte y un sahumerio. Varios nenes desfilaron con ellas (supongo que son hijos o nietos de las socias), cada uno con un cartel de una región distinta de Bolivia. Una nena vestida y peinada con mucho cuidado lleva una bandera argentina. Dos mujeres detrás una bandera boliviana.

El locutor anuncia “ Hace 18 años que hacemos este festejo.... Estamos tan lejos de nuestra tierra... esta queridísima argentina que nos ha cobijado... Nuestros hijos ya son argentinos, pero ellos llevan a Bolivia en la sangre

Al terminar el desfile volvemos a charlar con la presidenta de la asociación. Todavía tiene el sahumerio en la mano. Las mujeres toman coca mezclada con chicha. Nos ofrecen un vaso para challar a Cristo, a la virgen de Copacabana y a la pacha. Nos invitan a hacer lo mismo y después a comer con ellas en el salón. Le pregunto a la presidenta si han venido sus hijos "Nooo, mis hijos no me quieren ni ver asi, si me ven se mueren"

Pasado el mediodía mucha gente va llendo para el salón de la Colectividad. Solo pueden entrar "los invitados especiales", los feriantes y quienes desfilaron. Allí

\footnotetext{
Es importante considerar que la estructura de las fiestas patrias bolivianas en Argentina presenta gran continuidad año a año: discursos de apertura, desfiles, comidas, torneos artísticos y deportivos, premiación, bailes colectivos.
} 
desde el palco se sigue animando la fiesta, se sirve comida y hay números de canto y danza en los que participan adultos y niños. Las autoridades de la colectividad tambien bailan. Afuera se suceden los partidos de futbol donde participan sobre todo niños y jóvenes pero también adultos (en años anteriores he registrado que parte de la fiesta consiste en la entrega de trofeos a los equipos ganadores). Los más chicos juegan en varios inflables que han puesto frente al salón.

Cuando termina la comida desfilan afuera los grupos de danza compitiendo por distintos premios. La locutora reitera la importancia de transmitir "nuestras costumbres a nuestros hijos, nuestros retoños en este suelo"

(extracto de registro del 4 de Agosto de 2012. Festejo de la Independencia de Bolivia)

Además de las situaciones festivas, más o menos institucionalizadas, en contextos familiares esta transmisión y visibilizacion se registra en la preparación de platos típicos de Bolivia, en la recurrente proyección a los niños de videos sobre programas y danzas de Bolivia. Se advierte en la fuerte expectativa puesta en lo que los viajes a Bolivia y el conocimiento de los parientes que viven alla puedan implicar para los niños que se han criado en Argentina. Con respecto a la lengua, las expectativas parecen más complejas, al tiempo que se advierte el deseo de los adultos de que los niños hablen o entiendan la lengua quechua, se registra también la retracción de esta lengua en los niños y jóvenes, posiblemente fruto de las apuestas escolares (siendo la escuela un lugar donde hablar la lengua quechua se señala como un problema)

Las preocupaciones de los adultos por la discontinuidad en la transmisión intergeneracional se registran particularmente en sus comentarios acerca de la poca participación de los jóvenes en las organizaciones y al desconocimiento de sus hijos sobre Bolivia.

Los padres se preguntan permanentemente por las referencias de identificación que efectivamente operan en ellos, advierten que sus hijos están interpelados por múltiples discursos y referencias, señalan su incertidumbre sobre el posicionamiento de las nuevas generaciones al tiempo que apuestan por la inclusión en la nueva sociedad, porque hablen bien el castellano, realicen trayectorias escolares largas, se desenvuelvan "acá", etc.

La preocupación por la transmisión de "una forma de ser" asociada a "lo boliviano" con atributos como respetuoso, trabajador, obediente, se fortalece en la representación del contacto con argentinos como contaminante y potencial fuente de contagio de prácticas en los jóvenes como el robo, las drogas, el alcohol. En consonancia con ello se registra la referencia añorada a las formas escolares más disciplinadas en Bolivia, con referencias a los castigos físicos, la prolijidad y pulcritud, el trabajo con más cantidad de contenidos) ${ }^{9}$.

\footnotetext{
Recientemente hemos advertido que para muchos la valoración del orden y la disciplina se justifican en referencias tanto a lo andino como a lo evangélico. Futuras indagaciones deberán profundizar esta relación considerando que una cantidad significativa de pobladores del barrio asiste a las iglesias evangélicas
} 
En Escobar se advierte como una población objeto de fuertes prejuicios en la sociedad de destino y en un contexto de pobreza, da muestras reiteradas de su intención de seguir estando vinculada a la sociedad de origen y, como vimos en el relato de la fiesta, apuesta a que las nuevas generaciones "lleven a Bolivia en la sangre". Nominaciones como "bolivianos de segunda generación", condensando-una referencia espacial - Bolivia- y una temporal-generación -, resultan reveladoras de los dilemas con los que esta población proyecta las pertenencias nacionales de los niños y jóvenes y la preocupación por la continuidad en la transmisión generacional.

Los registros de campo hicieron evidente que las referencias a procesos históricos asociados a Bolivia, el proceso migratorio, la conformación del barrio en general no se realizan en situaciones que respondan a un objetivo explícito ni claramente definido de transmisión de la memoria del grupo, sino más bien que estas referencias se producen en el marco de múltiples diálogos y prácticas y en forma fragmentada, dispersa e informal; estos relatos y narraciones aparecen más o menos espontáneamente en la dimensión más cotidiana, aunque como vimos, tambien los registramos en formatos más instituidos en las celebraciones. En este aspecto anticipamos que se producen distancias significativas con la forma explícita, planificada y formalizada con que los relatos históricos se transmiten generalmente en el contexto escolar. Por otra parte, si bien el formato más instituido de las fiestas comunitarias coincide con dispositivos escolares, veremos como la continuidad de los aspectos representados y exaltados de "lo boliviano" en las fiestas comunitarias se diferencia de la fluctuación en la valoración de lo boliviano en las imágenes y relatos escolares.

\section{ENTRE LA FIJACIÓN Y LA OMISIÓN DE LA MEMORIA EN LA ESCUELA}

En el barrio hay dos escuelas públicas. A ellas asiste una cantidad significativa de niños bolivianos e hijos de bolivianos. Numerosas situaciones vividas en los patios, las entradas y salidas, los actos y las clases muestran a las escuelas como espacios relevantes para analizar las tensiones identitarias en la localidad ${ }^{10}$.

En la primera, advertimos explícitos desacuerdos en torno a reconocerla o no como "la escuela de los bolivianos". Lo mismo se plasmó en un incidente sumamente elocuente para pensar en las disputas en torno a las imágenes y memorias legítimas. En el año 2010 en ocasión del bicentenario de la revolución de Mayo se produjeron situaciones y propuestas de

- En trabajos anteriores sostuvimos la imagen de que ambas instituciones funcionaban en una lógica inversa de marcación/desmarcacion con lo boliviano (Novaro, 2015). Las situaciones que aquí se reproducen parcialmente y que fueron registradas en el año 2014 y 2015 con posterioridad a la elaboración de ese trabajo nos llevaron a relativizar la imagen de esta polaridad. 
acercamiento, encuentro y convocatoria con la colectividad boliviana, si bien desde imágenes y símbolos bastante estereotipados: se pintó la entrada de la escuela con la bandera argentina y boliviana, una mujer andina o chola, ataviada con amplias polleras y una larga trenza, junto con un gaucho; se izaron dos banderas se entonaron ambos himnos en algunos actos, en la cartelera se publicaron noticias de la Colectividad. En años posteriores todo esto generó profundos debates entre el personal de la escuela, ya que muchos docentes entendían que era necesario dejar en claro que "esta no es la escuela de los Bolivianos". Finalmente en el año 2014 los murales fueron blanqueados.

En esta institución el acercamiento a la colectividad y la habilitación para otras memorias e imágenes estuvo muy asociado a la presencia de una asistente social boliviana en el gabinete de la escuela. Serios conflictos se vincularon a su partida de la escuela. En ese contexto, el equipo directivo reivindicaba como acción formativa que todos los años los niños de la escuela viajaban a Rosario para la jura de la bandera argentina.

En la otra escuela, la más prestigiosa y demandada del barrio, lo andino, lo boliviano, lo indígena en principio parecía ausente en la estética de puertas, paredes y actos. Aparentemente se trataba de una presencia omitida y negada, tras el discurso igualador. Tras la apariencia aparentemente desmarcada de esta institución, otras marcas, identificaciones y memorias se legitimaban como universales en discursos, carteleras y proyectos: el catolicismo, el castellano, la patria, la bandera. Como en muchas escuelas argentinas la centralidad del relato de la historia nacional en las clases de historia excluía otros relatos. En esta escuela año a año se festeja el día de la tradición. Los registros dan cuenta de que el sentido de lo que se asocia a la tradición va variando año a año: bailes "nuestros", el chamamé, el pericón, con alguna nota de color local que por ejemplo da lugar a la presentación de caporales en los actos.

En el año 2014 en las clases de danzas la mamá de una nena de la escuela en acuerdo con la profesora, dio clases a los chicos enseñando tinnkus, morenada y caporales. Lo mismo finalizó con una muestra de caporales el dia de la tradición. Vale considerar que la madre que promocionó esta actividad es integrante de la cooperadora de la escuela, y tambien de la asociación de mujeres y participante en actividades de la Colectividad,

Los siguientes extractos de registros permiten hacerse una imagen de las clases de danza y los festejos escolares del dia de la tradición, aparentemente únicos lugares donde "lo boliviano" encuentra un espacio legítimo de expresión.

En el aula los chicos en general parecen relajados y contentos. La profesora de danza se acerca a algunos que no se suman a la actividad, trata de convencerlos pero finalmente si no quieren no insiste. Después de hablar un rato de los trajes 


\begin{abstract}
de varias danzas, Dora (la mama de una niña que ha venido a enseñarles "bailes de Bolivia") propone bailar caporales, algunos dicen: "si caporales!!!”. Bailan con bastante entusiasmo

Dora les pregunta si alguno estuvo en la fiesta de ayer. Era por un patrono, algunos dicen que sí. Muestra una revista de Bolivia con imágenes de danzas. Les pregunta cuanto creen que pesa el traje de los hombres. Dice que 150 kilos, "pero bailan con tanto entusiasmo que no se dan cuenta".

Bailan primero las chicas, algunas que al principio no lo hacían terminan sumándose. La profesora de danza dice que hacen muy bien los pasos pero no mueven el cuerpo. Dora les propone que cierren los ojos y se imaginen que no hay nadie. "Se baila con el corazón (se lo toca) hay que sentirlo". La portera llama algunos alumnos para ir al comedor. Se van varios pero algunos que habitualmente lo hacen prefieren quedarse bailando.

Dora pregunta a la maestra si el baile se podrá mostrar en algún acto, fin de año. La maestra sugiere el dia de la tradición en noviembre... (Extracto del registro de una clase de danza, 2014)
\end{abstract}

Luego de haber observado clases en muchas instituciones, resulta significativo la alusión a lo emocional, el entusiasmo de los chicos. Este sentimiento se tradujo, aparentemente, en el acto donde los alumnos bailaron. El comentario general fue "bailaron todos, vieras el entusiasmo que tenían los chicos argentinos". El año siguiente la actividad no continuó.

El acto del dia de la tradición en el 2015 fue inaugurado por los discursos de una maestra comentando "tradición es lo que nos da identidad.... Vamos a cantar el himno hoy más patriótico que nunca”. El acto será una sucesión de números: cuentos, danzas, canciones de distintos orígenes y estilos. Este los caporales fueron bailados solo por tres niños.

Además de las festividades, el registro de clases y cuadernos es otra puerta de entrada a las formas de reconstrucción del pasado y representación del presente.

Seguimos el desarrollo de la secuencia "pueblos indígenas" en cuarto y migraciones en sexto.

Los cuadernos de cuarto dan cuenta de que los alumnos comenzaron con una novedosa propuesta para trabajar su propia historia. Los títulos puestos en los cuadernos invitaban a la reflexión sobre el propio pasado ("Por aquí, por allá", "Donde estarás", "Nos conocemos, nos ubicamos", "Cómo es el lugar donde vivís", "Qué lugares conoces", "Observamos fotos antiguas y actuales"). Según testimonios escritos y el relato de la maestra los niños fueron invitados a acercar fotos, referir a acontecimientos personales, varios chicos entrevistaron a sus padres etc. Sin embargo, cuando semanas después desarrollaron el tema Pueblos indígenas, nada se dijo sobre las propias marcas étnicas de ellos y sus familias, el tema comenzó con la definición de "los que antes llamamos indios y ahora llamamos aborígenes" "fueron los primeros que vinieron a Argentina", para seguir con las tradicionales exposiciones de pueblos (seleccionando tehuelches y guaraníes, según la 
docente por ilustrar un grupo nómade y uno sedentario), enumerando, vivienda, ambiente, armas, vestimentas, con inclusiones fragmentarias de referencias que presuponían que con ellos había paz y se respetaba el ambiente.

La lejanía y la ajenidad de lo indígena se refuerza considerando la forma en que el tema es aludido en las carteleras de la escuela

Para el 12 de octubre, Día de la diversidad cultural y tambien para el dia del aborigen y de las Américas aparecen discursos e imágenes en la cartelera que aluden a la importancia de la revalorización y el fortalecimiento de sus identidades y de su cultura".

Asi, el uso de tercera persona tanto en los cuadernos como en las carteleras (sus, para hablar de algo que corresponde a "otros") define el lugar del autor y presupone el posicionamiento del lector. Construye un otro cuya historia es narrada como ajena.

Además de los sentidos que adquiere el desarrollo del tema pueblos indígena, tambien el modo en que se presentan en historia las migraciones resulta relevante para la temática que nos convoca. La modalidad, como ya registramos en investigaciones en otras escuelas suele ser aludir al tema solo en referencia a la migración europea que llega al país entre fines del siglo XIX y principios del XX. Se habla entonces del impulso que se dio a la migración en el contexto de organización del estado y en ocasiones, de "sus" costumbres y "su" voluntad de progreso. No encontramos ningún registro de que en las escuelas del barrio se tratara como contenido de historia o de geografía la migración latinoamericana. Esta omisión del tema no es una excepción en las escuelas argentinas.

Si bien en el espacio festivo, como vimos, se habilita de alguna manera la presencia de "lo boliviano" (lo que no es menor, considerando las estéticas escolares tradicionales), advertimos que esta presencia se borra en las clases de ciencias sociales. Ateniéndonos al desarrollo de las temáticas registradas, en una institución que se dice igualadora y con una docente que parecía compenetrada con el tema y el grupo, se hace evidente la necesidad de pensar en las consecuencias de presentar temas tan cercanos a los alumnos como si fueran lejanos (lo indígena como atributo del pasado de tehuelches y guaraníes, los procesos migratorios atravesando la vida de los europeos de principio de siglo XX). La omisión de las experiencias de los niños y sus familias aleja de la escuela los conocimientos socialmente relevantes sobre las mismas temáticas.

\section{RefLeXiones finALES}

Las familias y organizaciones, en formatos espontáneos y en otros relativamente instituidos apuestan porque sus hijos participen de los espacios comunitarios y, de esa manera, del colectivo boliviano. 
Frente a estas expectativas, es necesario pensar el sentido de los silencios, las ausencias y las presencias fragmentadas de "lo boliviano" en ambas escuelas. Para ello recuperamos las afirmaciones de Boaventura de Souza Santos (2008) acerca de la importancia de atender al modo en que ciertas realidades se producen como no existentes.

En el caso analizado, resulta necesario analizar las formas de puesta en acto (un mural, una danza), de lo que venía siendo invisibilizado y silenciado. Si bien la presencia de lo boliviano en la escuela sigue siendo limitada, fragmentada y su formato folklorizado, plantea cierta ruptura con las imágenes y estéticas legitimas.

En las clases de historia la referencia a lo indígena como algo ajeno y pasado niega su contemporaneidad en las trayectorias y experiencias de los niños del barrio. La restricción de las alusiones a la migración europea y la omisión de la migración latinoamericana en una escuela poblada por niños cuyas familias han atravesado la experiencia migratoria transfronteriza, constituye un modo evidente de negación de su pasado.

La escuela no aparece claramente como un espacio de disputa por la memoria para las familias del barrio que en general parecen colocar las expectativas de continuidad identitaria fuera de ella. Pero la escuela sí parece ser un espacio de disputa para los mismos actores escolares; el ejemplo de las imágenes andinas y bolivianas pintadas y luego blanquedas en la puerta de una de las escuelas habla por sí mismo de referencias y memorias invocadas y borradas.

La dinámica de ambas escuelas hace que nos preguntemos cómo construir (otra vez en términos de Souza Santos) cuidadas formas de la traducción del silencio y de presentar lo ausente. En este intento sigue vigente el desafío de incluir y legitimar otras voces, de habilitar otros diálogos desde la escuela con las familias y organizaciones. Las condiciones de posibilidad de ello desbordan el sistema educativo e interpelan a una sociedad todavía en deuda con la construcción de miradas y dispositivos más igualitarios y tambien con la legitimación de múltiples representaciones del pasado y el presente y de proyecciones futuras.

Todo esto toma un color especial en una localidad donde gran parte de los adultos al tiempo que esperan mantener cierta distinción como colectivo y mantener a Bolivia como un referente significativo, desean su integración a la nueva nación y demandan que la escuela incluya a sus hijos. En este contexto, es necesario seguir pensando porque en las escuelas las marcas asociadas a lo boliviano siguen viviéndose como un problema. Dar lugar a otras imágenes y relatos, construir memorias complementarias y no divergentes, resulta un acto de igualdad si entendemos la inclusión en sentido amplio, y no como un premio a la renuncia a las propias imagenes y a la propia historia. 


\section{REFERÊNCIAS BIBLIOGRÁFICAS}

BENENCIA, R.. Migrantes bolivianos en la periferia de ciudades argentinas: procesos y mecanismos tendientes a la conformación de territorios productivos y mercados de trabajo. En S. Novick, (Comp.) Las migraciones en América Latina. Políticas, culturas y estrategias. Buenos Aires: Catálogos, 2008.

CANDAU, Joel. Memoria e identidad. Buenos Aires: Ediciones del Sol, Serie antropológica, 2008.

CERRUTTI, Marcela. 2009 Diagnóstico de las poblaciones de inmigrantes en la Argentina. Buenos Aires, Serie de Documentos de la Dirección Nacional de Población, Secretaría de Interior, Ministerio del Interior, Organización Internacional para las Migraciones, Marzo 2009.

CARRETERO, Mario; ALBERTO Rosa y GONZALEZ, M Fernanda (comp) Enseñanza de la historia y memoria colectiva. Buenos Aires, Paidos, 2013.

GAVAZZO, Natalia. "Acceso diferencial a la ciudad. Identificaciones y estereotipos entre los hijos de inmigrantes bolivianos y paraguayos en Buenos Aires” En SSIIM Paper Series, vol 8. Febrero 2011. www.unescochair-iuav.it. 2011.

GONZÁLEZ GUARDIOLA, Lola. De Bartolina Sisa al comité de receptoras de alimentos de El Alto. España: Ediciones de la Universidad de Castilla La Mancha Colección Humanidades, 2000. GRIMSON, Alejandro. Relatos de la diferencia y la igualdad. Buenos Aires: EUDEBA, 1999..

HALBWACHS, Maurice. La memoria colectiva. Buenos Aires. Miño y Dávila. 2011.

NOVARO, Gabriela (2015) Familias, asociaciones y escuelas: tensiones en las identificaciones nacionales de niños migrantes. En Linhas Críticas. Revista da Facultade de Educacao - UnB Brasil, Dossier de Antropología y Educacion. Coord Amurabi Olivera. p. 77-93.

NOVARO, Gabriela; DIEZ, María Laura. ¿Una inclusión silenciosa o las sutiles formas de la discriminación? Reflexiones a propósito de la escolarización de niños bolivianos. En: Courtis, Corina; Pacecca, María Inés (comp.) Discriminaciones étnicas y nacionales: un diagnóstico participativo. Buenos Aires: Editores del Puerto y Asociación por los Derechos Civiles, 2012. 37-57.

NOVARO, Gabriela. "Procesos de identificación nacional en población migrante: continuidades y quiebres en las relaciones intergeneracionales", Revista de Antropología Social, Universidad Complutense de Madrid Noviembre de 2014, p. 157-179.

NOVICK, Susana. Migraciones y políticas en Argentina. Tres leyes para un país extenso. En Novick, Susana (comp.). Las migraciones en América Latina. Políticas, culturas y estrategias. Buenos Aires: Catálogos, 2008. p. 131-151.

POLLAK, Michael "Memoria, olvido, silencio". Estudos Históricos. Rio de Janeiro, Vol. 2, № 3. 1989, p. 3-15.

PACECCA María Inés; COURTIS, Corina. Inmigración contemporánea en Argentina: Dinámicas y políticas. Serie Población y Desarrollo - CEPAL www.eclac.org. 2008. 
PIZARRO, Cynthia. Inmigración y discriminación en el lugar de trabajo. El caso del mercado frutihortícola de la colectividad boliviana de Escobar. Revista Estudios Migratorios Latinoamericanos, Buenos Aires, Publicaciones del CEMLA No 63, 211-244. 2007.

RIVERA, Silvia. La noción de derecho o las paradojas de la modernidad poscolonial : indígenas y mujeres en Bolivia ». Revista Aportes Andinos. N 11. http://www.uasb.ec/padh. Octubre 2004.

SASSONE, Susana; DE MARCO, G. Inmigración limítrofe en la Argentina. Revista del Centro de Estudios Migratorios Latinoamericanos, 1991.

SOUZA SANTOS, Boaventura. Conocer desde el sur. Para una cultura política emancipatoria. La Paz: Clacso, CIDES-UMSA- Plural, 2008. 